\title{
Enumeração de Campylobacter spp. e presença de Campylobacter jejuni em carcaças de frango no Estado de Minas Gerais
}

\author{
Enumeration of Campylobacter spp. and presence of Campylobacter jejuni in broiler carcasses in the \\ State of Minas Gerais, Brazil
}

Afonso de Liguori Oliveira ${ }^{\mathrm{I}}$ Roseane Batitucci Passos de Oliveira ${ }^{\mathrm{II}}$

\section{RESUMO}

Campilobacteriose é uma zoonose de distribuição mundial, com repercussões importantes na saúde pública $e$ um grande impacto socioeconômico. As rotas de transmissão ao homem das espécies de Campylobacter são o contato direto com animais portadores, água ou alimentos contaminados e é mais comumente associado ao consumo de carne de frango. $O$ objetivo deste estudo foi detectar e enumerar Campylobacter spp. por um método rápido (SimPlate ${ }^{\circledR}$ ) e pelo método convencional (plaqueamento direto em ágar mCCD), determinando a frequência e o nível de contaminação em 75 amostras de carcaças de frangos (25 Pré-chiller e 25 Póschiller obtidos em abatedouros sob inspeção federal no Estado de Minas Gerais e 25 amostras congeladas, coletadas no comércio verejista). As amostras avaliadas, independentemente do método utilizado, apresentaram Campylobacter spp. em $56,0 \%$ das carcaças antes do chiller e 44,0\% após o chiller. A contagem das amostras congeladas se apresentou abaixo do limite de detecção do método. Das 75 amostras testadas, 34,7\% foram positivas para Campylobacter spp. Das amostras positivas, 38,5\% foram identificadas como $\boldsymbol{C}$. jejuni e, entre estas, o maior número de $\boldsymbol{C}$. jejuni foi obtido nas carcaças de frango antes do chiller (42,9\%), seguido de carcaça de frango após o chiller $(36,4 \%)$. O estudo mostrou que a detecção $e$ enumeração é variável, embora em nenhuma das amostras destinadas ao comércio foram obtidas contagens acima da dose infectante estabelecida. $O$ uso do SimPlate ${ }^{\circledR}$ foi adequado $e$ equivalente ao plaqueamento direto em ágar $m C C D e$ apresentou uma melhor taxa de recuperação de células de Campylobacter spp.

Palavras-chave: carne de frango, Campylobacter spp., Campylobacter jejuni, identificação, contaminação.

\section{ABSTRACT}

Campylobacteriosis is a worldwide distribution zoonosis, with significant repercussions on public health and with a high socioeconomic impact. Routes of transmission of Campylobacter species to man are direct contact with carrier animals, contaminated water or food and it is most commonly associated with consumption of chicken meat. The objective of this study was to detect and enumerate the Campylobacter spp. by a rapid method (SimPlate ${ }^{\circledR}$ ) and and conventional method (direct plating on $m C C D A$ ) and determine frequency and level of contamination in 75 broiler carcasses $(25$ pre-chill; 25 postchill at establishments under federal inspection in the State of Minas Gerais, Brazil and 25 frozen broiler carcass samples taken from the retail trade). Evaluated samples, regardless of the technique used, detected the presence of Campylobacter spp. in $56.0 \%$ before the chiller and $44.0 \%$ after the chiller. Counts of the frozen samples were below the detection limit of the method. Of the 75 samples tested, $34.7 \%$ were positive for Campylobacter spp. and that, $38.5 \%$ were identified as $\boldsymbol{C}$. jejuni. Among them, the largest number of $\boldsymbol{C}$. jejuni obtained was from the carcass of the chicken before the chiller $(42.9 \%)$, followed by chicken carcass after the chiller (36.4\%). The study showed that the detection and enumeration is variable, although in none of the samples intended for trade has been obtained scores above the infective dose. The use of SimPlate ${ }^{\circledR}$ technique was appropriate and equivalent to direct plating on agar $m C C D$ and showed a better recovery rate cells of Campylobacter spp..

Key words: broiler meat, Campylobacter spp., Campylobacter jejuni, identification, contamination.

\section{INTRODUÇÃO}

A campilobacteriose é uma zoonose de distribuição mundial, que causa gastroenterite em humanos e animais, e pode ser adquirida por contaminação cruzada ou cocção inadequada de produtos de origem animal, particularmente de carne

'Departamento de Tecnologia e Inspeção de Produtos de Origem Animal, Escola de Veterinária, Universidade Federal de Minas Gerais (UFMG), Av. Antônio Carlos, 6627, 31270-901, Belo Horizonte, MG, Brasil. E-mail: afonso@ vet.ufmg.br. Autor para correspondência.

"IDepartamento de Alimentos, Faculdade de Farmácia, UFMG, Belo Horizonte, MG, Brasil. 
de frango (OYARZABAL et al., 2005; FSA, 2005;). A Autoridade Europeia para a Segurança Alimentar (EFSA, 2011) estimou que ocorram nove milhões de casos anuais de campilobacteriose humana, que resultam em 350.000 dias não trabalhados e custos totais anuais de 2,4 bilhões de Euros.

Algumas espécies como o Campylobacter jejuni, $\boldsymbol{C}$. coli, $\boldsymbol{C}$. lari e $\boldsymbol{C}$. upsaliensis são termófilas (WASSENAAR \& NEWELL, 2006) e são as principais espécies causadoras de quadros de diarreia (WHO, 2000). C.jejuni é responsável por aproximadamente 80 a $90 \%$ dos surtos de campilobacteriose (ALTER \& SCHERER, 2006; DEBRUYNE et al., 2008; OIE, 2011).

A prevalência de Campylobacter spp. em carcaças de frango é variável. Na União Europeia (UE), a prevalência média é de 75,8\%, com valores variando entre $4,9 \%$ e $100 \%$, sendo que as contagens relatadas para carcaças são muito variáveis entre os países da $\mathrm{UE}$, variando de $<10^{1} \mathrm{UFC} \mathrm{g}^{-1}$ a $>10^{4} \mathrm{UFC} \mathrm{g}^{-1}$ (EFSA, 2010). O padrão microbiológico para carnes de aves em relação ao Campylobacter spp. ainda não está estabelecido. AAutoridade Europeia para a Segurança dos Alimentos (EFSA, 2011) tem proposto, para aves, um limite crítico entre $5 \times 10^{2}$ e $10^{3} \mathrm{UFC} \mathrm{g}^{-1}$. Entretanto, dados da Agencia de Padrões Alimentares da Inglaterra (FSA, 2005) e do Centro para Controle e Prevenção de Doenças dos Estados Unidos (CDC, 2011) indicam que a dose infectante é baixa, sendo estabelecida entre 500 e 800 unidades formadoras de colônia de Campylobacter spp. que podem causar doença. $\mathrm{O}$ objetivo do presente estudo foi detectar e enumerar Campylobacter spp. usando o método rápido SimPlate ${ }^{\circledR}$ Campylobacter e por plaqueamento direto em ágar mCCD (método convencional), determinando a frequência e o nível de contaminação, realizando identificação morfológica e bioquímica de Campylobacter jejuni em carcaças de frango no Estado de Minas Gerais.

\section{MATERIAL E MÉTODOS}

Foram realizadas cinco coletas, em abatedouros sob Inspeção Federal. Em cada uma delas, foram coletadas cinco carcaças de frango antes do resfriamento em chiller $(n=25)$ e outras cinco após o resfriamento $(\mathrm{n}=25)$. Nos mesmos períodos, no comércio varejista, foram feitas cinco coletas de cinco amostras de carcaça frango congeladas $(n=25)$, perfazendo um total de 75 amostras, entre carcaças resfriadas e congeladas. No momento de coleta das amostras no abatedouro, a temperatura dos tanques e a cloração da água do chiller foram mensuradas com termômetro digital (GULTON, São Paulo, Brasil) e Kit para teste de cloro livre (MERCK Microquant ${ }^{\circledR}$, Darmstadt,
Alemanha), respectivamente. As amostras colhidas no abatedouro foram pesadas individualmente, em saco plástico de amostragem, e enxaguadas com $400 \mathrm{~mL}$ de água peptonada tamponada (USDA, 2011), para se estabelecer as contagens por grama de carcaça. Das amostras de carcaças congeladas, foram colhidos $25 \mathrm{~g}$ de amostra em pontos distintos e homogeneizadas em Homogeneizador MA-440/CF (Marconi, Piracicaba, Brasil), com $225 \mathrm{~mL}$ de água peptonada tamponada $\left(10^{-1}\right)$.

Para o método rápido, foi retirada uma alíquota de 1,0mL do líquido de enxágue de cada carcaça, e da diluição inicial das carcaças congeladas. Cada alíquota foi adicionada, separadamente aos frascos de SimPlate ${ }^{\circledR}$ Campylobacter C-CI (BioControl América Latina - Campinas, SP, Brasil), preparados de acordo com as recomendações do fabricante. Estes foram incubados, sem inverter, a $42^{\circ} \mathrm{C}$, por $48-52 \mathrm{~h}$, em câmara de anaerobiose (BUG BOX, Yorkshire, Inglaterra), em microaerofilia $\left(\mathrm{N}_{2} 85 \%, \mathrm{CO}_{2} 10 \%, \mathrm{O}_{2} 5 \%\right)$, conforme NACMCF (2007), e realizadas as contagens de acordo com as recomendações do fabricante,

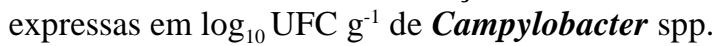

Para o método convencional, quatro alíquotas de $0,25 \mathrm{~mL}$ foram colhidas do líquido de enxágue das carcaças (abatedouro) e da diluição inicial das amostras congeladas, sendo distribuídas entre quatro placas de ágar carvão cefoperazona desoxicolato modificado mCCDA(CM0739-OXOID ${ }^{\circledR}$, Hampshire, Inglaterra) com suplemento (SR0155 - OXOID ${ }^{\circledR}$, Hampshire, Inglaterra), e incubadas conforme NACMCF (2007). Foram contadas as colônias típicas e os resultados expressos em $\log _{10}$ $\mathrm{UFC}^{-1}$ de Campylobacter spp. Para as avaliações bioquímicas e identificação da espécie, foram utilizadas como cepas padrão Campylobacter jejuni NCTC 11351 e Campylobacter coli NCTC 11366. Foram coletadas do conjunto de placas (quatro por amostra) cinco colônias típicas para os testes de aglutinação em látex, catalase, oxidase, sensibilidade ao ácido nalidíxico e à cefalotina e hidrólise do hipurato e do indoxil acetato (BRASIL, 2003; ALTER \& SCHERER, 2006;ANDRADE et al., 2010).

\section{RESULTADOS E DISCUSSÃO}

Os níveis de cloro livre na água do chiller se mantiveram acima de $2 \mathrm{ppm}$ em todas as datas de amostragem e dentro dos limites estabelecidos pela legislação (BRASIL, 1998).

Foi detectada a presença de Campylobacter spp. nas amostras de carcaça de frango do abatedouro, sendo as médias de contagem no pré-chiller $\left(2,19 \pm 0,30 \log _{10} \mathrm{UFC}^{-1}\right)$ maiores que as do pós-chiller $\left(0,55 \pm 0,22 \log _{10}\right.$ UFC $\left.\mathrm{g}^{-1}\right)$, independentemente do método utilizado (Tabela 1). Contagens mais elevadas 
Tabela 1 - Média das contagens ( $\log _{10} \mathrm{UFC} \mathrm{g}^{-1}$ ) de Campylobacter spp. em carcaças de frango antes e após o chiller, método rápido (SimPlate ${ }^{\circledR}$ ) ou convencional (agar mCCD).

\begin{tabular}{|c|c|c|c|c|}
\hline \multirow{2}{*}{ Mês da análise } & \multicolumn{4}{|c|}{ - } \\
\hline & Simplate ${ }^{\circledR}$ & mCCDA & Simplate ${ }^{\circledR}$ & mCCDA \\
\hline out $/ 10$ & $2,69 \pm 0,07^{1}(2 / 5)^{2}$ & $1,98 \pm 0,27(2 / 5)$ & $0,63 \pm 0,21(2 / 5)$ & $0,41 \pm 0,22(2 / 5)$ \\
\hline nov/10 & $2,04 \pm 0,18(4 / 5)$ & $1,90 \pm 0,26(4 / 5)$ & $0,38 \pm 0,22(2 / 5)$ & $0,39 \pm 0,21(2 / 5)$ \\
\hline $\operatorname{mar} / 11$ & $2,05 \pm 0,37(2 / 5)$ & $1,67 \pm 0,16(2 / 5)$ & $0,57 \pm 0,12(3 / 5)$ & $0,54 \pm 0,14(3 / 5)$ \\
\hline $\mathrm{abr} / 11$ & $2,02 \pm 0,47(3 / 5)$ & $1,83 \pm 0,15(3 / 5)$ & $0,65 \pm 0,17(2 / 5)$ & $0,32 \pm 0,11(2 / 5)$ \\
\hline mai/11 & $2,14 \pm 0,38(3 / 5)$ & $1,80 \pm 0,08(3 / 5)$ & $0,61 \pm 0,33(2 / 5)$ & $0,43 \pm 0,21(2 / 5)$ \\
\hline Média & $2,19 \pm 0,30(14 / 25)$ & $1,83 \pm 0,18(14 / 25)$ & $0,55 \pm 0,22(11 / 25)$ & $0,44 \pm 0,20(11 / 25)$ \\
\hline
\end{tabular}

1 - Médias e desvio-padrão das contagens $\left(\log _{10} \mathrm{UFC}^{-1}\right)$ de Campylobacter spp.

$2-\mathrm{n}^{\mathrm{o}}$ de amostras positivas $/ \mathrm{n}^{\mathrm{o}}$ total de amostras.

foram relatadas por KUANA et al. (2008) em frangos, após a depenadeira (antes do chiller) com valores de $5,15 \log _{10}$ UFC carcaça $^{-1}$ e 4,22log $\log _{10}$ UFC carcaça $^{-1}$ após chiller. No geral, os valores obtidos neste trabalho para as carcaças antes do chiller variaram de $1,67 \log _{10}$ UFC $\mathrm{g}^{-1}\left(\cong 47 \mathrm{UFC} \mathrm{g}^{-1}\right)$ a $2,69 \log _{10} \mathrm{UFC} \mathrm{g}^{-1}\left(\cong 490 \mathrm{UFC} \mathrm{g}^{-1}\right)$, dependendo do método utilizado.

Por outro lado, as médias de contagem nas amostras de carcaças resfriadas (depois do chiller) apresentaram uma redução significativa, que variou entre $1,13 \log _{10} \mathrm{UFC} \mathrm{g}^{-1}$ e $2,06 \log _{10} \mathrm{UFC} \mathrm{g}^{-1}$, valores abaixo do observado nas carcaças antes do chiller, sendo a variação das contagens entre e $0,32 \log _{10}$ UFC $\mathrm{g}^{-1}$ a $0,65 \log _{10} \mathrm{UFC} \mathrm{g}^{-1}\left(\cong 2,09 \mathrm{UFC} \mathrm{g}^{-1}\right.$ a $\left.4,47 \mathrm{UFC} \mathrm{g}^{-1}\right)$. Assim, observa-se que ocorre redução da contaminação na etapa de resfriamento. Essa etapa, portanto, contribui para a diminuição do risco de um surto de campilobacteriose, pois, tomando-se o valor médio de contagem $\left(0,55 \log _{10} \mathrm{UFC} \mathrm{g}^{-1}\right)$ obtido para as amostras de carcaças do pós-chiller e considerando uma ingestão de $100 \mathrm{~g}$ dessas carcaças, não haveria possibilidade de ingestão de um número de células acima da dose infectante de Campylobacter spp. estabelecida, que é 500 células viáveis (WHO, 2000; EFSA, 2011). Dessa forma, a adoção das boas práticas de fabricação em toda a cadeia produtiva, associada aos procedimentos adequados para evitar a contaminação cruzada e aplicação de tratamento térmico do produto para o consumo final são de suma importância para impedir o risco potencial em desencadear um surto de campilobacteriose.

Das 25 amostras de carcaça congeladas analisadas, as médias das contagens foram abaixo do limite de detecção dos métodos $\left(<0,3 \log _{10} \mathrm{UFC} \mathrm{mL}^{-1}\right)$ (Tabela 2). Porém, em algumas amostras, observou-se crescimento compatível com perfil de Campylobacter spp., tanto pela técnica do SimPlate ${ }^{\circledR}(16,0 \%)$ quanto no plaqueamento direto em ágar $\mathrm{mCCD}(4,0 \%)$. Desse modo, pode-se inferir que ocorre uma redução de contagem após a estocagem congelada, fato este também relatado por ALTER et al. (2005) e EL-SHIBINY et al. (2009). Apesar de se observar essa redução, SAMPERS et al. (2010) alertam para o fato de que uma parte da população desses microrganismos pode sobreviver ou apresentar injúrias subletais, quando congeladas, e, em certas condições, sairem do estado de viáveis não cultiváveis (VNC).

Das 75 amostras analisadas, 34,7\% foram positivas para Campylobacter spp. Esse valor situase bem abaixo da média encontrada na União Europeia, que é de 75,8\% (EFSA, 2010). Para a identificação de Campylobacter jejuni, a partir das 75 amostras analisadas, foram obtidos 130 isolados, a partir do plaqueamento direto em ágar mCCD (Tabela 3). Destes, $27,7 \%$ foram identificados com $\boldsymbol{C}$. jejuni, sendo que o

Tabela 2 - Média das contagens $\left(\log _{10}\right.$ UFC $\left.\mathrm{g}^{-1}\right)$ de Campylobacter spp. em carcaças de frango congeladas, obtidas por método rápido (SimPlate ${ }^{\circledR}$ ) ou convencional (agar mCCD).

\begin{tabular}{lcl}
\hline Mês da análise & Simplate & Ágar mCCD \\
\hline out/10 & $<0,30(1 / 5)^{1}$ & $<0,30(1 / 5)$ \\
nov/10 & $<0,30(2 / 5)$ & $<0,30(0 / 5)$ \\
mar/11 & $<0,30(0 / 5)$ & $<0,30(0 / 5)$ \\
abr/11 & $<0,30(0 / 5)$ & $<0,30(0 / 5)$ \\
mai/11 & $<0,30(1 / 5)$ & $<0,30(0 / 5)$ \\
Média & $<0,30(4 / 25)$ & $<0,30(1 / 25)$ \\
\hline
\end{tabular}

1- Médias das contagens $\left(\log _{10} \mathrm{UFC} \mathrm{g}^{-1}\right)$ de Campylobacter spp. $\left(\mathrm{n}^{\mathrm{o}}\right.$ de amostras positivas $/ \mathrm{n}^{\mathrm{o}}$ de amostras analisadas). 
Tabela 3 - Identificação de Campylobacter jejuni, a partir dos isolados obtidos por plaqueamento direto em ágar mCCD a partir de amostras positivas de carcaça de frango.

\begin{tabular}{lcccc}
\hline Tipo de Amostra & $\begin{array}{c}\mathrm{N}^{\mathrm{o}} \text { de amostras positivas/ } \\
\mathrm{N}^{\mathrm{o}} \text { amostras }(\%)\end{array}$ & $\begin{array}{c}\mathrm{N}^{\mathrm{o}} \mathrm{de} \\
\text { isolados }\end{array}$ & $\begin{array}{c}\text { Amostras }+(\%) / \\
\mathrm{N}^{\mathrm{o}} \text { isolados }(\%) \text { Campylobacter jejuni }\end{array}$ & $\begin{array}{c}\text { Amostras - }(\%) / \\
\mathrm{N}^{\mathrm{o}} \text { isolados }(\%) \text { Campylobacter spp. }\end{array}$ \\
\hline CA-A $^{1}$ & $14 / 25(56,0)$ & 70 & $6(42,9) / 25(35,7)$ & $8(57,1) / 45(64,3 \%)$ \\
CA-G & $11 / 25(44,0)$ & 55 & $4(36,4) / 11(20,0)$ & $7(63,6) / 44(80,0 \%)$ \\
CA-C & $1 / 25(4,0)$ & 5 & $0(0,0) / 0(0,0)$ & $1(100,0) / 5(100,0 \%)$ \\
Total & $26 / 75(34,7)$ & 130 & $10(38,5) / 36(27,7)$ & $16(61,5) / 94(72,3 \%)$ \\
\hline
\end{tabular}

1 - CA-A (carcaças antes do chiller); CA-G (carcaças depois do chiller - Gotejamento); CA-C (carcaças congeladas).

maior número de isolados caracterizados como $\boldsymbol{C}$.jejuni foram os obtidos a partir das carcaças de frango antes do chiller $(35,7 \%)$, seguido da carcaça de frango após o chiller $(20,0 \%)$. Os isolados obtidos das amostras congeladas não resultaram em identificação positiva de C. jejuni. Esses resultados diferem do que foi observado por outros autores, que relatam ser esta a espécie predominante em carne de frango (EFSA, 2010; ZHAO et al., 2010). Esse fato pode estar relacionado ao volume de troca de água que é recomendado no Brasil para o pré-chiller e chiller (BRASIL, 1998), diferentemente do que ocorre na Europa. São também inferiores aos relatados por ALTER et al. (2005), que isolaram $\boldsymbol{C}$.jejuni em $72,1 \%$ das amostras de carcaças de perus antes do resfriamento, tendo observado, após o chiller, uma redução nessa população para $67,4 \%$. De modo interessante, ao final de $24 \mathrm{~h}$ de resfriamento, a população de $\boldsymbol{C}$. jejuni foi de $25,6 \%$ das amostras, valores bem próximos ao observados em nosso trabalho.

\section{CONCLUSÃO}

As amostras de carcaças de frango resfriadas e congeladas produzidas no Estado de Minas Gerais, por abatedouros avícolas inspecionados, apresentaram baixo nível de contaminação por Campylobacter spp.

O resfriamento das carcaças reduz as contagens desses microrganismos e também de $\boldsymbol{C}$. jejuni, uma vez que o número de amostras positivas para nas amostras antes do chiller foi superior às observadas após o chiller.

Nas amostras congeladas não foi detectada a presença de $\boldsymbol{C}$. jejuni e as contagens de Campylobacter spp. foram baixas $\left(<0,3 \log _{10} \mathrm{UFC} \mathrm{mL}^{-1}\right)$, o que sugere que o congelamento é um processo que afeta a sobrevivência desse patógeno.

Embora ainda não exista um padrão oficial, o Brasil, como o maior exportador mundial de carne de frango, deve estar atento a esse patógeno, embora, neste trabalho, todas as amostras avaliadas seriam de qualidade aceitável, dentro do padrão atualmente proposto na Europa (EFSA, 2010).

\section{AGRADECIMENTO}

Os autores agradecem ao financiamento APQ n . 01778-09 recebido da Fundação de Amparo à Pesquisa do estado de Minas Gerais(FAPEMIG).

\section{REFERÊNCIAS}

ALTER, T.; SCHERER, K. Stress response of Campylobacter spp. and its role in food processing. Journal of Veterinary Medicine, n.53, p.351-357, 2006. Disponível em <http:// onlinelibrary.wiley.com/doi/10.1111/j.1439-0450.2006.00983.x/ pdf $>$. Acesso em 05 abr. 2010. doi: 10.1111/j.14390450.2006.00983.x.

ALTER,T. et al. Distribution of Campylobacter jejuni strains at different stages of a turkey slaughter line. Food Microbiology, v.22, p.345-351, 2005. Disponível em <http://ac.els-cdn.com/ S0740002004001078/1-s2.0-S0740002004001078-main. pdf?_tid=dc3a6a0e-2765-11e2-b8e7-00000aab0f02\&acdnat= 1352133101_07369eb0b27607f16dda66aae953771e>. Acesso em 10 abr. 201. doi: 10.1016/j.ijfoodmicro.2008.03.030.

ANDRADE, R.B. et al. Métodos diagnósticos para os patógenos alimentares: Campylobacter sp., Salmonella sp. e Listeria monocytogenes. Arquivos do Instituto Biológico, v.77, n.4, p.741-750, 2010.

BRASIL, Ministério da Agricultura, Pecuária e Abastecimento. Portaria n.210, de 10 de Novembro de 1998. Regulamento técnico de inspeção tecnológica e higiênico sanitária de carne de aves. Diário Oficial da União de 26/11/1998. seção 1. p.226. Brasil, 1998.

BRASIL. Ministério da Agricultura, Pecuária e Abastecimento. Secretaria de Defesa Agropecuária. Instrução Normativa $\mathrm{N}^{\circ} 62$, de 26 de agosto de 2003. Métodos Analíticos Oficiais para Análises Microbiológicas para Controle de Produtos de Origem Animal e Água. Diário Oficial da União, Brasília, DF, 18 set. 2003, seção 1, p. 14-51. Disponível em: <http://extranet.agricultura.gov.br/ sislegis-consulta/consultarLegislacao.do?operacao= visualizar\&id=2851>. Acesso em: 17 ago. 2011. 
CDC. Vital signs: incidence and trends of infection with pathogens transmitted commonly through food. Foodborne Diseases Active Surveillance Network, 10 U.S. Sites, 1996-2010, United States of America. Morbidity and Mortality Weekly Report, v.60, n.22, p.749-775, 2011. Disponível em: <http://www.cdc.gov/ $\mathrm{mmwr} / \mathrm{preview} / \mathrm{mmwrhtml} / \mathrm{mm} 6022 \mathrm{a} 5 \mathrm{htm}>$. Acesso em: 14 set. 2011

DEBRUYNE, L. et al. Taxonomy of the Family Campylobacteriaceae. In: NACHAMKIN, I. (Ed.). Campylobacter. Washington: ASM, 2008. p.3-27.

EL-SHIBINY, A. et al. Survival at refrigeration and freezing temperatures of Campylobacter coli and Campylobacter jejuni on chicken skin applied as axenic and mixed inoculums. International Journal of Food Microbiology, v.131, p.197-202, 2009. Disponível em: <http://ac.els-cdn.com/S016816050900138X/1s2.0-S016816050900138X-main.pdf?_tid=a0527a06-2768-11e289 e $0-00000$ a ab0f6c \&acdnat $=1352134289 \_88543210$ 8b35d1f19fd9f6efd52ef69c>. Acesso em 23 jun 2011. doi: http:// dx.doi.org/10.1016/j.ijfoodmicro.2009.02.024.

EFSA (EUROPEAN FOOD SAFETY AUTHORITY). Analysis of the baseline survey on the prevalence of Campylobacter on broiler batches and of Campylobacter and Salmonella on broiler carcasses in the EU, 2008. Part A: Campylobacter and Salmonella prevalence estimates. EFSA Journal, v.8, n.3, p.1503, 2010 .

EFSA (EUROPEAN FOOD SAFETY AUTHORITY). Scientific opinion on Campylobacter in broiler meat production: control options and performance objectives and/or targets at different stages of the food chain. EFSA Journal, v.9, n.4, p.2105, 2011. Disponível em: <http://www.efsa.europa.eu/en/ efsajournal/pub/2105.htm>. Acesso em: 10 ago. 2011.

FSA (FOOD STANDARDS AGENCY). Advisory committee on the microbiological safety of food: second report on Campylobacter advises the food standards agency on the microbiological safety of food. Published by Food Standards Agency March 2005 FSA/0986/0605 p. 185, 2005. Disponível em: <http:/ /www.food.gov.uk/multimedia/pdfs/acmsfCampylobacter.pdf>. Acesso em: 15 dez. 2010.

KUANA, S.L. et al. Ocorrência de Campylobacter em lotes de frangos de corte e nas carcaças correspondentes. Ciência Animal Brasileira, v.9, n.2, p.480-486, 2008.

NACMCF (NATIONAL ADVISORY COMMITTEE ON MICROBIOLOGICAL CRITERIA FOR FOODS). U.S. Department of Agriculture, Food Safety and Inspection Service. Supplement Analytical Utility of Campylobacter Methodologies. Journal of Food Protection, v.70, p.241-250, 2007. Disponível em: <http:/ /www.fsis.usda.gov/PDF/NACMCF_JFP_Manuscript_06-361.pdf〉. Acesso em: 20 nov. 2010.
OIE (WORLD ORGANISATION FOR ANIMAL HEALTH). Terrestrial Animal Health Code. 20.ed. 2011, Chapter 2.9.3. Campylobacter jejuni and Campylobacter coli. Disponível em: <http://www.oie.int/en/international-standard-setting/ terrestrial-manual>. Acesso em: 15 jul. 2011.

OYARZABAL, O.A. et al. Evaluation of agar plates for direct enumeration of Campylobacter spp. from poultry carcass rinses. Applied and Environmental Microbiology, v.71, p.33513354, 2005. Disponível em: <http://www.ncbi.nlm.nih.gov/pmc/ articles/PMC1151831/pdf/1969-04.pdf >. Acesso em: 22 abr. 2010. doi: 10.1128/AEM.71.6.3351-3354.2005.

SAMPERS, I. et al. Survival of Campylobacter spp. in poultry meat preparations subjected to freezing, refrigeration, minor salt concentration, and heat treatment. International Journal of Food Microbiology, v.137 , p.147-153, 2010. Disponível em: <http://ac.els-cdn.com/S0168160509006072/1-s2.0S0168160509006072-main.pdf?_tid=00cfee72-276e-11e2$9812-00000$ a a c b $362 \&$ acdnat $=1352136598 \_221$ 32cac3e73a4b626dfa984b2b876d5>. Acesso em 03 mar. 2012. doi: 10.1016/j.ijfoodmicro.2009.11.013.

USDA (UNITED STATES DEPARTMENT OF AGRICULTURE). Food Safety and Inspection Service, Office of Public Health Science. MLG 41.01 Page 1 of 16. Isolation, identification and enumeration of Campylobacter jejuni/coli/lari from poultry rinse and sponge samples. Revision: 01 Effective: 08/01/11, 16p. Disponivel em: <http://www.fsis.usda.gov/PDF/MLG_41_01.pdf>. Acesso em: 14 ago. 2011.

WASSENAAR, T.M.; NEWELL, D.G. The genus Campylobacter. In: DWORKIN, M. (Ed.). The prokaryotes a handbook on the biology of bacteria. V.7: Proteobacteria: delta and epsilon subclasses. Deeply Rooting Bacteria. 3.ed. New York: Springer Science, 2006. Cap. 3.5.1. p. 119-138.

WHO (WORLD HEALTH ORGANIZATION). Department of Communicable Disease Surveillance and Response. The increasing incidence of human campylobacteriosis. Report and Proceedings of a WHO Consultation of Experts. Copenhagen, Denmark. 13. Methods for isolation of Campylobacter from humans, animals, food and water. Frederick James Bolton, 2000. p.87-93. Disponível em: <http://whqlibdoc.who.int/hq/2001/ who_cds_csr_aph_2001.7.pdf>. Acesso em: 19 jan. 2011.

ZHAO, S. et al. Antimicrobial resistance of Campylobacter isolates from retail meat in United States between 2002-2007. Applied and Environmental Microbiology, n.76, p.79497956, 2010. Disponível em: <http://www.ncbi.nlm.nih.gov/pmc/ articles/PMC3008252/pdf/1297-10.pdf >. Acesso em: 03 mai. 2011. doi: 10.1128/AEM.01297-10. 